\title{
APRENDIZADOS NO CURSO DE RESIDÊNCIA AGRÁRIA: JUVENTUDE RURAL, AGROECOLOGIA E EDUCOMUNICAÇÃO
}

\section{LEARNING IN THE COURSE OF AGRARIAN RESIDENCE: RURAL YOUTH, AGROECOLOGY AND EDUCOMUNICAÇÃO}

\author{
Anderson Bezerra Candido ${ }^{1}$ https://orcid.org/0000-0002-5250-1777 \\ Cláudio Ubiratan Gonçalves ${ }^{2}$ https://orcid.org/0000-0002-0777-4506
}

\footnotetext{
${ }^{1}$ Mestrando em Geografia pela Universidade Federal de Pernambuco - UFPE. Laboratório de Estudos e Pesquisas sobre Espaço Agrário e Campesinato - LEPEC. E-mail: profandersonbezerra@ hotmail.com

2 Professor do Departamento de Geografia da Universidade Federal de Pernambuco - UFPE. Laboratório de Estudos e Pesquisas sobre Espaço Agrário e Campesinato - LEPEC. E-mail: biragrario@gmail.com
}

\section{RESUMO}

O curso de residência agrária: Juventude Rural, Agroecologia e Educomunicação contou com a formação técnico profissional de 46 (quarenta e seis) estudantes pertencentes a áreas de conflitos agrários no estado de Pernambuco. O curso teve seu início no ano de 2014 e término no ano de 2017. Fez parte do Programa Nacional de Educação Reforma Agrária-PRONERA e contou com a parceria da Comissão Pastoral da Terra-CPT Nordeste II, Universidade Federal de Pernambuco-UFPE, Ministério do Desenvolvimento Agrário-MDA e Instituto Nacional de Colonização e Reforma Agrária-INCRA. Buscaremos relatar e analisar as contribuições do curso para a vida dos educandos a partir dos planos de aulas, relatorias de atividades realizadas, relatos dos educandos arquivados em mídias digitais e entrevistas com educadores e agentes pastorais. Observando o andamento e póscurso conseguimos observar mudanças nas relações sociais, novas formas de organização, criação de hortas comunitárias, comunicação com outras comunidades que estão em processo de luta pela terra, busca por novos saberes e conhecimentos agroecológicos e soberania alimentar.

Palavras-chave: Residência Agrária. Agroecologia. Educomunicação.

\begin{abstract}
The agrarian residency course: Rural Youth, Agroecology and Educommunication had the professional technical training of 46 students belonging to areas in agrarian conflicts in the state of Pernambuco, started in 2014 and ended in 2017. It was part of the Program National Education for Agrarian Reform-PRONERA and had the partnership of the Pastoral Land Commission-CPT Nordeste II, Federal University of Pernambuco-UFPE, Ministry of Agrarian Development-MDA and National Institute of Colonization and Agrarian Reform-INCRA. We will seek to report and analyze the course's contributions to the students 'lives from the lesson plans, reports of activities carried out,
\end{abstract}


students' reports filed in digital media and interviews with educators and pastoral agents. Observing the progress and post-course, we can observe changes in social relations, new forms of organization, creation of community gardens, communication with other communities that are in the process of fighting for land, search for new knowledge and agroecological knowledge and food sovereignty.

Keywords:Agrarian Residence. Agroecology. Educommunication.

\section{CONSIDERAÇÕES INICIAIS}

Este relato é fruto de um conjunto indissociável de experiências vivenciadas no/do curso de residência agrária: Juventude Rural, Agroecologia e Educomunicação e que serviu como objeto de estudo para a elaboração, problematização e fundamentação do trabalho de conclusão de curso (TCC) em licenciatura em Geografia pela Universidade Federal de Pernambuco (UFPE).

A modalidade do curso em Residência Agrária tem a intenção de contribuir para uma maior aproximação das universidades e as áreas de reforma agrária, de acordo com Molina (2009). É dentro dessa proposta que o Laboratório de Estudo e Pesquisa, Espaço Agrário e Campesinato (LEPEC) da UFPE, junto a CPT, atuou nas áreas de reforma agrária em Pernambuco, conhecendo as dificuldades e buscando soluções que respeitassem as especificidades e os saberes-fazeres camponeses. Foi respeitando a vida dos alunos que o curso se fez acontecer, dentro da proposta pedagógica da alternância, para o qual os educandos aprenderam em espaços e tempos sociais diferentes, no qual o tempo escola e tempo comunidade se conectaram. No tempo escola, os educandos aprenderam formas de organização camponesa, os conteúdos são ligados às suas práticas profissionais, sociais, econômicas e políticas. No tempo comunidade, o aluno trabalha, convive com a família e instituições sociais do seu cotidiano, porém agora sua vida faz parte do conteúdo do curso do qual faz parte, levando-o a refletir sobre suas práticas, sobre suas dificuldades e sobre a busca por soluções que reduzam as desigualdades existentes no campo.

O curso de Residência Agrária contou com alunos que vivenciam a questão agrária nas mesorregiões do Agreste, Zona da Mata Norte e Sul e Sertão do estado de Pernambuco, estando em momentos diferentes do processo de luta pela terra e direitos essenciais como: educação, saúde, organização comunitária, soberania alimentar, permanência na terra para reprodução da vida e do trabalho. 
Mapa 1: Mesorregiões com estudantes que participaram do Curso do Residência Agrária em Pernambuco.

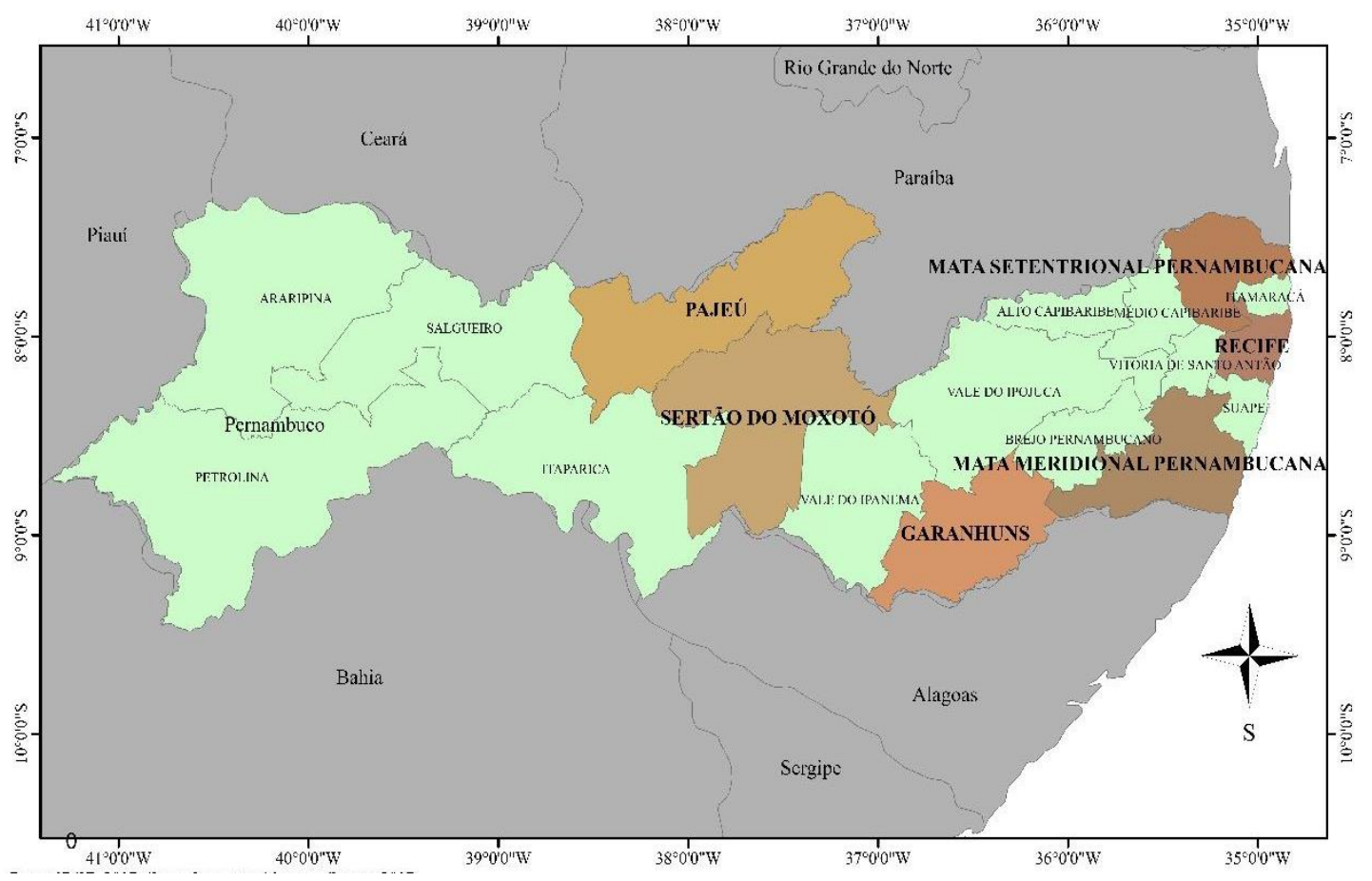

Fonte: IBGE, 2017. Com adaptações feitas por Santos, 2017.

\section{OS TERMOS DA QUESTÃO}

Compreendemos o processo de aprendizagem como um dos fundamentos principais na prática pedagógica desenvolvida ao longo do curso de Residência Agrária. O processo de aprendizagem não é linear e cumulativo e traz muito da experiência vivenciada que é compartilhada pelos sujeitos envolvidos.

As práticas pedagógicas que respeitem a concepção de aprendizagem em foco devem apoiar-se em duas idéias fundamentais: A de que todo conhecimento provém da prática social e a ela retorna; E a de que o conhecimento é um empreendimento coletivo, nenhum conhecimento é produzido na solidão do sujeito, mesmo porque essa solidão é impossível (GIUSTA, 2013, p. 35).

O objetivo geral do curso $^{1}$ seria a formação de jovens entre 15 e 29 anos em agroecologia e sua forma educomunicacional, sendo uma proposta de fortalecimento da vida no campo de forma sustentável, trazendo para uma perspectiva de horizontalidade os conhecimentos científicos e saberes populares.

\footnotetext{
${ }^{1}$ Universidade Federal de Pernambuco - UFPE. Projeto Juventude Rural: Edocomunicação e Agroecologia. Nov., 2014. Recife, 24 p.
} 
Originalmente o curso foi dividido em 6 (seis) tempos escola, durante os quai os estudantes ficariam reunidos, teriam estudos teóricos e práticos e buscariam demonstrar como aqueles conhecimentos poderiam ser utilizados dentro das áreas de reforma agrária nas quais eles residiam. Porém, ao todo ocorreram 7 (sete) tempos escola, sendo o sétimo um momento de apresentação de trabalhos de conclusão de curso elaborados pelos estudantes e uma confraternização.

Figura 1: Alunos debatendo sobre a questão agrária.

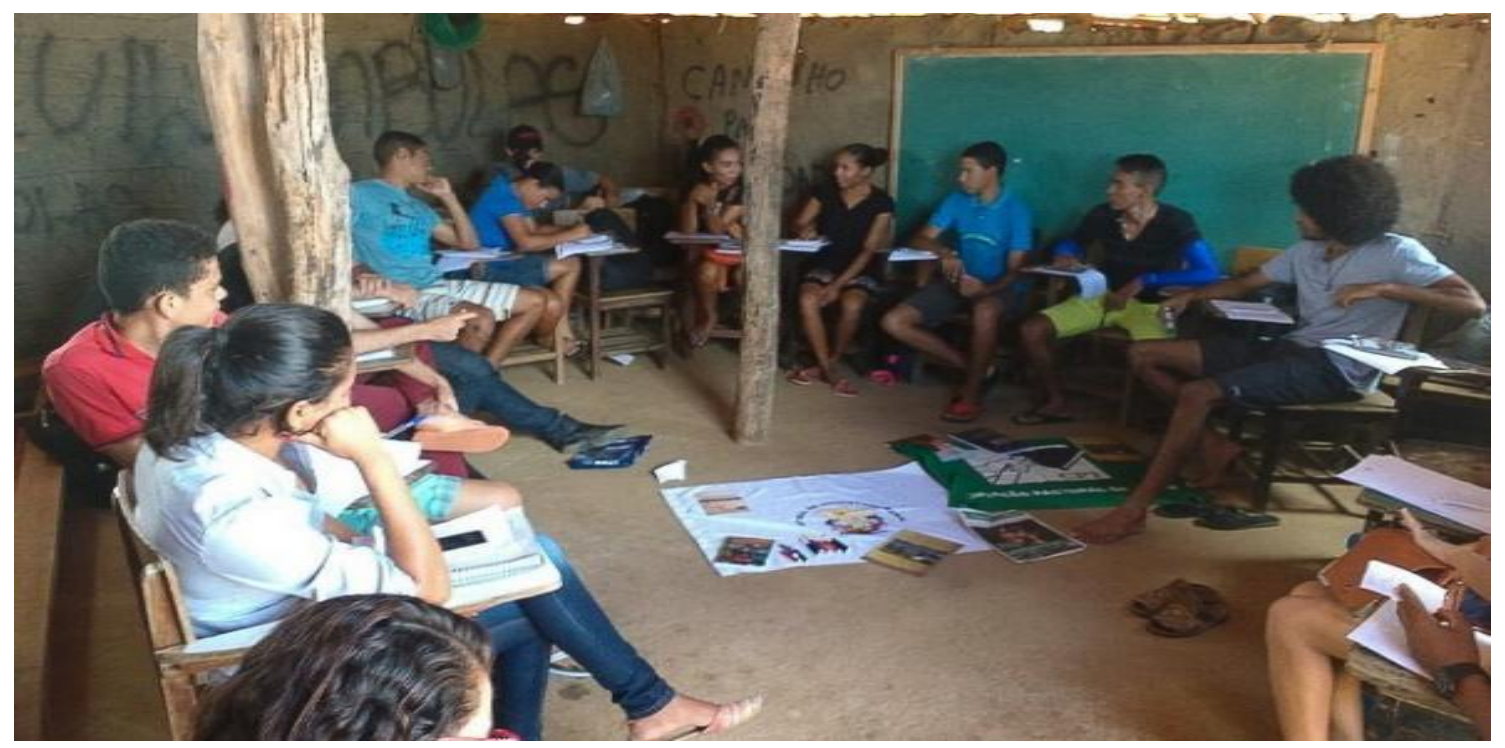

Fonte: CPT, 2017.

\section{OS TEMPOS E ESPAÇOS DO CURSO DE RESIDÊNCIA AGRÁRIA}

O primeiro tempo escola teve como principal objetivo a apresentação dos alunos junto aos agentes pastorais, professores da UFPE, monitores, responsáveis do INCRA e professores responsáveis pelo andamento do tempo escola e elaboração do acordo de convivência. Em relação à parte conteudista e de formação do encontro, foram estudados e aprofundados os conceitos de educação e comunicação, que são a base para a concepção de educomunicação. Foram debatidos gêneros de educomunicação, articulações e parcerias, produção, pré-edição, edição e finalização de produções coletivas. $O$ intuito desse módulo foi aprender a utilizar os meios de comunicação de massa a favor dos estudantes residentes, demonstrando omo a educomunicação pode ser uma ferramenta política utilizada nos conflitos existentes em seus territórios em disputa. No final de cada tempo escola era deliberada uma atividade que seria executada no tempo comunidade. Nessa transição foi solicitado um relatório sobre o manejo do solo e suas dificuldades. Os estudantes também deveriam interagir e conversar com 
moradores e trabalhadores de suas respectivas comunidades a respeito da trajetória histórica e política, descobrir quem foram as lideranças, os conflitos históricos e os atuais.

No segundo encontro os alunos apresentaram os resultados das pesquisas realizadas em suas comunidades. Numa aula expositiva , lhes foram apresentados diferentes modos de manejo do solo e como a agricultura em grande escala do agronegócio ameaça as formas ancestrais de uso da terra. Logo depois, os alunos construíram um croqui para representar espacialmente suas comunidades e apresentar como o solo é manejado. Trabalhou-se os malefícios do uso de agrotóxico, a diferença entre um alimento orgânico e agroecológico e questões de soberania e segurança alimentar. Os alunos apresentaram em esquetes teatrais como são suas vidas no campo, como eles manejam o solo, como são as relações de sociabilidade e como seria o impacto dos agrotóxicos nas suas produções e saúde coletiva.

O terceiro tempo escola esteve voltado ao manejo agroecológico e orgânico. Os alunos desenvolveram atividades de intercâmbio e receberam a visita de moradores, de outros camponeses e técnicos do Centro de Desenvolvimento Agroecológico Sabiá ${ }^{2}$ mostrando a importância da agroecologia, da prática da agrofloresta e do processo de transição agroecológica para uma alimentação saudável e garantia de uma renda. Os alunos apresentaram suas primeiras produções audiovisuais, feitas dentro de suas comunidades com a participação dos moradores, esses mostrando como manejam o solo, como fazem o beneficiamento dos produtos e até a comercialização nas feiras das regiões. Alguns estudantes do curso de agroecologia e educomunicação tiveram a oportunidade de representar os demais alunos e participarem no IV Congresso Nacional da CPT ${ }^{3}$ em Rondônia; Eles relataram as experiências e buscaram expor aos demais como os jovens estão se organizando na luta pela terra em âmbito nacional. Outra atividade pedagógica importante realizada foi a construção da linha do tempo utilizando informações, dados e memórias sobre as áreas de onde os estudantes são residentes.

\footnotetext{
${ }^{2}$ O Centro de Desenvolvimento Agroecológico Sabiá é uma organização não governamental com sede na capital Pernambucana, Recife, fundada em 1993, que desenvolve atividades juntos aos agricultores familiares em diversas regiões do Estado a partir dos princípios da agroecologia. (Centro De Desenvolvimento Agroecológico Sabiá. Disponível em: $<$ Quem Somos - Centro de Desenvolvimento Agroecológico Sabiá - Recife - Pernambuco - Brasil Centro Sabiá (centrosabia.org.br)>. Acesso em: 22 de agosto de 2012).

${ }^{3}$ IV Congresso Nacional da Comissão Pastoral da Terra (CPT), ocorreu de 12 a 17 de julho de 2015, em Porto Velho, Rondônia. Comemorou-se os 40 anos da fundação da CPT e foi discutido com diversos povos formas de enfrentar o novo cenário político e econômico vivenciado pelo país. (CENTRO DE ESTUDOS BÍBLICOS. Disponível em: <IV Congresso Nacional comemora os 40 anos da Comissão Pastoral da Terra - CPT - CEBI>. Acesso em: 22 de agosto de 2021).
} 
Figura 2: Preparação para uma apresentação.

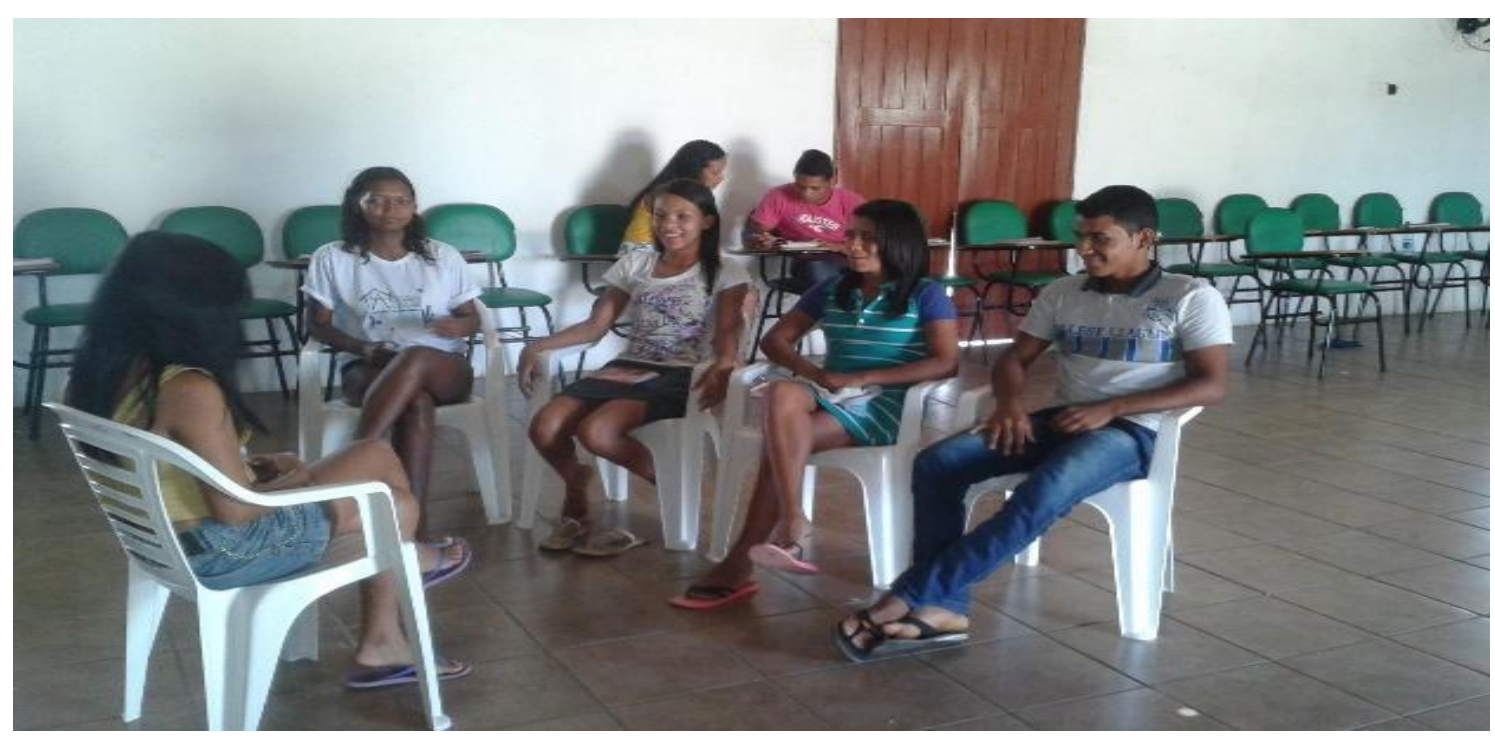

Fonte: CPT, 2017.

Os três módulos anteriores aconteceram no Santuário das Comunidades ${ }^{4}$, em Caruaru, agreste pernambucano, porém o quarto período aconteceu em Recife, no Campus da UFPE. Muitos alunos visitaram a universidade pela primeira vez e estava estampado no rosto de cada um e cada uma o contentamento com aquela experiência. Foi uma conquista estarem ali ocupando e frequentando um espaço público de que tanto ouviam falar e que agora fazia parte da rotina deles. Dentro do ambiente acadêmico, dos alunos residentes participaram da Jornada Universitária em Defesa da Reforma Agrária-JURA, do Lançamento do Caderno de Conflitos 2015 da CPT e das mesas redondas junto de professores e pró-reitores da instituição, agentes pastorais, representantes do INCRA. Foi um momento único e ideal para os alunos exporem a questão agrária existente no estado de Pernambuco.

Aconteceu também uma aula de campo, na qual os estudantes puderam conhecer o Centro Histórico de Recife e o Museu Cais do Sertão ${ }^{5}$, esse segundo sendo analisado pelos próprios estudantes da mesorregião do sertão, que analisaram quanto se sentiram representados no museu. Em reuniões na UFPE foram debatidos temas como sistema de produção do capital e capitalismo, homofobia/lesbofobia/transfobia no campo, juventude

\footnotetext{
${ }^{4}$ O Santuário das Comunidades foi construído por meio das Comunidades Eclesiais de Base. "Foi inspirado no sonho de organização, participação, formação e autonomia das Comunidades, o sonho do povo ter voz e vez". (Santuário das Comunidades. Disponível em: <Santuário das Comunidades: Quem Somos (santuariodascomunidades.blogspot.com)>. Acessado em: 22 de agosto de 2012).

${ }^{5}$ O Museu Cais do Sertão, localiza-se nos antigos Armazéns do Porto do Recife, traz exposições da cultura do Sertão Nordestino. (Visit.Recife. Disponível: <Museu Cais do Sertão - Visit Recife>. Acessado em: 22 de agosto de 2021).
} 
negra e etnias. Os debates foram carregados com muito estudos através de poesia, música, teatro, trazidos tanto pelos convidados quanto pelos estudantes.

O quinto módulo iniciou com a exibição do documentário Vida de Lona Preta ${ }^{6}$, produzido pela CPT e que conta a trajetória de luta pela terra dos familiares e de alguns dos alunos residentes. O debate sobre o documentário trouxe para os alunos não só um conteúdo e uma história familiar a serem debatidos, mas sim os saberes que servem para a prática de resistência para as pessoas que estão na linha de frente do conflito e que serão responsáveis por suas comunidades futuramente. Também foram produzidos fanzines e foi dialogado sobre a importância da escrita para a comunicação entre as comunidades. Os estudantes tiveram de aulas expositivas sobre a história e geografia da questão agrária brasileira a explicações sobre a conjuntura agrária do atual momento e a relação entre o movimento de migração dos jovens e a reforma agrária.

O interessante dessas aulas foi a participação dos estudantes, visto que eles se identificam com o conteúdo estudado, refletem, assimilam e conseguem produzir mais conhecimentos com diálogos e experiências. Novas perguntas e estratégias que sejam úteis para reprodução da vida no campo são suscitadas e com o isso o processo de ensino e aprendizagem é retroalimentados. Também foi abordado como o consumismo, uma das faces do sistema capitalista pode alterar as relações sociais e da natureza.

O sexto módulo foi um momento de reflexão a respeito dos módulos anteriores: como a construção do curso aconteceu e como ajudou nas relações dentro das áreas de reforma agrária no estado de Pernambuco. Foi solicitado aos alunos que criassem um mural com palavras da conjuntura política da época do início da chegada dos primeiros moradores na comunidade e como isso estava afetando as suas vidas ainda hoje. Numa reunião, da comunidade foi representada por um aluno, o qual demonstrou como as ferramentas e aprendizados em educomunicação vêm contribuindo para democratizar os saberes. Também foi criado um grupo de educomunicadores que ficariam responsáveis pelo diálogo entre as comunidades dos alunos residente e os agentes mediadores da Comissão Pastoral da Terra.

\section{CONSIDERAÇÕES FINAIS}

Durante o andamento do curso de residência agrária , foi observada uma maior participação dos alunos não só nas atividades realizadas no tempo escola, mas também

\footnotetext{
${ }^{6}$ Documentário Vida de Lona Preta. (Videoteca Virtual Gregório Bezerra. 2015. Disponível em: < Vida de Lona Preta - YouTube>. Acessado em: 22 de agosto de 2021).
} 
durante o tempo comunidade. Os alunos passaram a ocupar funções de lideranças dentro das suas comunidades e espaços de sociabilidade política. Foram criados e articulados grupos jovens, hortas comunitárias, e esse maior engajamento sociopolítico era refletido na participação dos alunos em atividades como, por exemplo, o congresso da CPT, reuniões dos movimentos sociais do campo e reivindicações junto às sedes das prefeituras de onde residiam.

Passaram também a entender o histórico conflito de luta pela terra, as formas que se manifestam as opressões, como manejar o solo de maneira sustentável, como manter a comunicação com outras áreas de luta pela reforma agrária, trocaram saberes tradicionais em relação à plantação e à comercialização dos excedentes. Alguns alunos não pararam neste curso: voltaram a ver a educação como forma de resistência e iniciaram cursos em outras instituições, como o Serviço de Tecnologia Alternativa- SERTA ${ }^{7}$.

Figur3: Mística Organizada pelos estudantes.

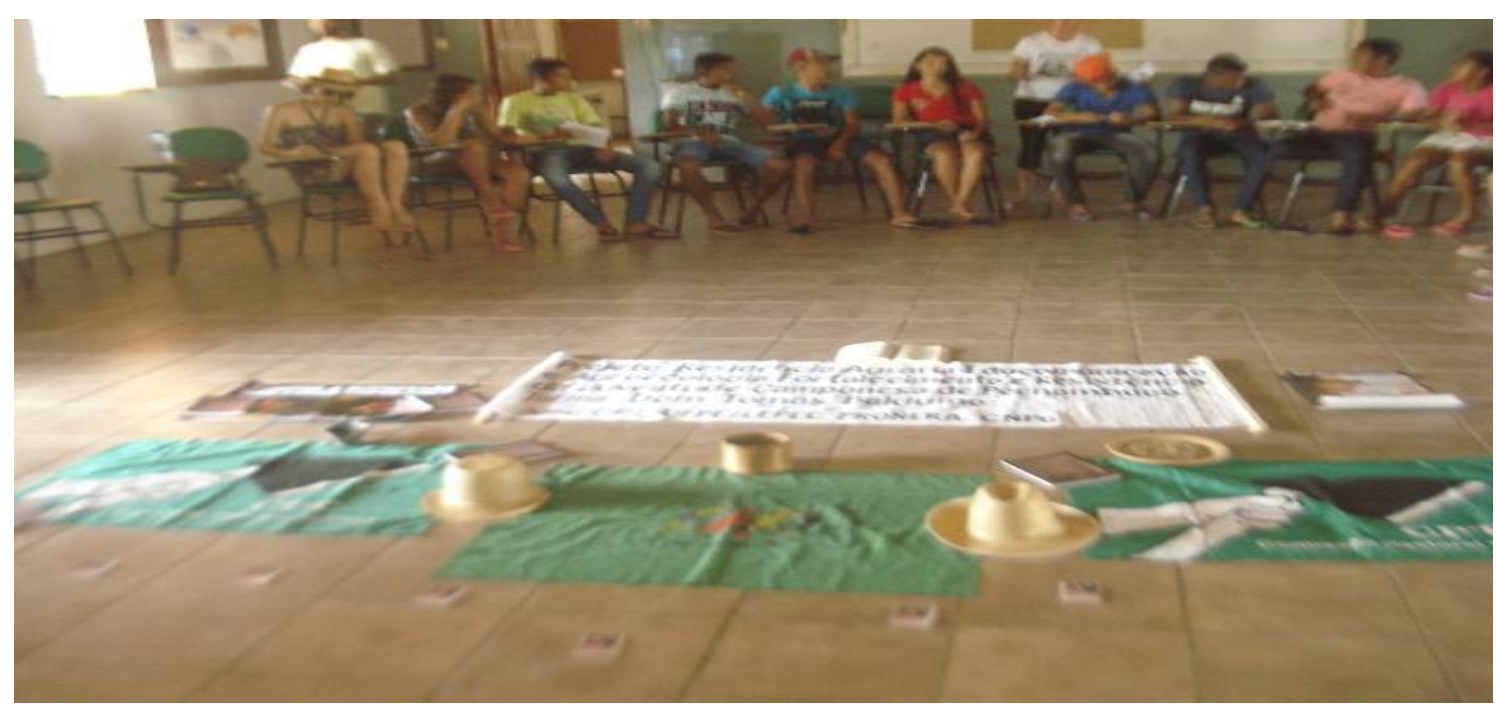

Fonte: CPT, 2017.

\section{REFERÊNCIAS}

GIUSTA, Agnela da Silva. Concepções de aprendizagem e práticas pedagógicas. Educação em Revista, v. 29 | n. 01, p. 17-36, Belo Horizonte, 2013.

\footnotetext{
${ }^{7}$ O SERTA é uma organização da Sociedade Civil de Interesse Público (Oscip), fundada em 1989, através da colaboração de agricultores e agricultoras, técnicos e educadores buscando a promoção da natureza, ao mesmo tempo garantindo melhores condições de vida para as pessoas do campo. Atua a partir de 2 (duas) Unidades Pedagógicas: no município de Ibimirim e outro no município de Glória do Goitá. Oferece curso técnico em Agroecologia, além de cursos livres de sistemas agroflorestais, hortas urbanas, manejo agroecológico do solo entre outros. (SERTA. Disponível em: 〈SERTA » O Serta $\rangle$. Acessado em: 20 de agosto de 2021).
} 
GONÇALVES, C. U.; PEREIRA, G. S.B. Relatos e Experiências Contraditórias no Magistério Superior do Campo: Reflexões a partir do ensino de Geografia e História. Revista Tamoios (Online), v. IV, p. 2-15, São Gonçalo, RJ, 2008.

MOLINA, M.C. et al. Educação do Campo e Formação Profissional: A experiência do Residência Agrária. MDA. Brasília, 2009.

Artigo recebido em: 29 de maio de 2021.

Artigo aceito em: 25 de agosto de 2021. Artigo publicado em: 13 de setembro de 2021. 